\title{
Editorial
}

\section{First Edition of Hahnemann's Organon: Celebrating its 200th Anniversary}

\author{
José Enrique Eizayaga \\ Invited Editor, International Journal of High Dilution Research, IJHDR
}

With this special issue, IJHDR celebrates the $200^{\text {th }}$ anniversary of the first edition of Hahnemann's Organon, published in 1810. By 1796, in a previous foundational article published in Hufeland's prestigious Journal of Practical Medicine [1], after criticizing with fine reasoning the usual ways of studying the "curative properties of medicinal substances", namely according to their chemical actions, their effects on animals, their external aspect or sensitive properties, their taxonomic classification, or the random use of multiple drugs by the so called empiricists, Hahnemann stated what can be regarded as one of the cornerstones of homeopathy: "The true physician, whose sole aim is to perfect his art, can avail himself of no other information respecting medicines, than - first, what is the pure action of each by itself on the human body? Second, what do observations of its action in this or that simple or complex disease teach us?"

Though it must now be recognized that Hahnemann was not the pioneer of the method of experimenting drugs in healthy volunteers or in self-experimentation [2], this conceptual and basic approach took an essential role in the development of homeopathy as a medical science. In this issue of the IJHDR, a paper by Jim Rogers refers to the history of Hahnemann's elaboration of the homeopathic pathogenetic trial, along with its potential biases and the latest ideas on how to overcome them [3].

In another paper included in this issue of IJHDR, Lex Rutten [4] calls our attention to a dangerous misconception homeopaths from Hahnemann to the present-time have relied on, as well as the possible way to correct it. Commonly accepted homeopathic knowledge states that it can be assumed that a given symptom belongs to the materia medica of a drug when it is elicited in healthy subjects during a pathogenetic trial and is confirmed by cured cases in clinical practice.

However, without more refined, comprehensible and strict criteria from an epidemiological point of view, the field of the materia medica becomes extremely fertile to accumulate countless entries of doubtful accuracy in repertories, based on single occurrences of symptoms. As Rutten clearly explains through the notion of likelihood ratio and Bayes's theorem - both well established tools of modern epidemiology - for a given symptom to be considered part of the materia medica of a homeopathic medicine, it must be observed in "cured" cases with a significantly greater prevalence than in the remainder of the population. Rutten's approach is grounded on remarkable clinical research [5].

In the same 1796 Essay, Hahnemann enounced the similia similibus principle, a second cornerstone of homeopathy: "We should imitate nature, which sometimes cures a chronic disease by superadding another, and employ in the (especially chronic) disease we wish to cure, that medicine which is able to produce another very similar artificial disease, and the former will be cured."

By this time, Hahnemann still believed that the larger the dose of medicine was, the greater its curative effect, "though with some danger to life." Therefore, he strongly recommended the use of small and increasing doses in order to achieve "mild and certain cures" [1]. 
The above mentioned first two cornerstones of homeopathy were soundly established with the publication of the Organon. There is a very interesting debate about the title and literary structure Hahnemann chose for this book, of which he prepared six different editions in the course of his life, and that initially he called Organon of the Rational Art of Healing. The Greek term Organon was originally given to Aristotle's set of treatises on logic, and it means instrument, in the sense of that which is useful for something else. In the course of time, it was repeatedly used by philosophers to name a set of methodological principles aiming at being used to find truth in some aspect [6]. This was probably Hahnemann's intention when he chose this particular name.

The term rational in the title disappeared from the second edition onwards. Unknown and more speculative are the reasons of why Hahnemann erased it. On the one hand, he was a scholarly very well trained doctor, but on the other, he was convinced that only experience was the right path to therapeutic knowledge. He himself advocated for a rational materia medica, as stated in the Organon: "In such a Materia Medica there is nothing conjectured, asserted without proof, imagined, invented; but all is the pure reply of Nature to careful questioning”(§ 121) [7].

The term rational appears many times in the first edition or the Organon, while it is very scarce in the sixth one, where conversely he raises strong criticism against rational medicine. An example of what could Hahnemann have understood for rational could be "The rational nature of the art of medicine manifests itself pre-eminently in the rejection of all systematic and other prejudices, in the refusal to act without good grounds, in the adoption of every possible measure to achieve the desired action, and in confining attention as much as possible to that which can be definitely ascertained” (§ 47) [7].

Therefore, we can find Hahnemann considering himself as rational but rejecting current rationalistic medicine for its disdain of experience along with excessive theorization, while rejecting also empiricists because of the lack of rationale in their experiences. One must keep in mind that this took place far away from the present-day concepts of science and epidemiology in medicine, and Hahnemann's doubts are thus understandable.

In this first edition of the Organon a third cornerstone of homeopathy was also definitively established - the use of diluted and shaken substances in therapeutics: "[...] the intimate mixture produced by adding a single drop of a tincture to a pound of water and shaking vigorously, if administered in doses of two ounces every two hours, will produce more effect than a single dose of eight drops of the tincture” (\$251).

Two other decisive notions which can be regarded as a fourth cornerstone came out clearly in this edition of the Organon, namely totality and individuality. Hahnemann along his whole life had a clear philosophical position against mechanistic theories, considering living beings as totalities: "[...] the human body is, in its living state, a unity, a complete and rounded whole. Every sensation, every manifestation of force, every interrelation of the material of one part, is intimately concerned with the sensation, force-manifestations and interrelations of all the other parts; no part can suffer without involving all the rest in suffering (greater or less) and in alteration. This oneness of life forbids the idea that any bodily disease can remain completely and absolutely local (§ 42-43).

This totalizing conception included of course disease and treatment, reaching the level of a genuine psychosomatism: "By means of this medicine employed internally (not externally) the general disease-condition of the body is removed simultaneously with the local disorder, and the first and the last are cured together. This proves that the local malady depends on a disease of the body as a whole, and is only to be regarded as one of the most important symptoms in a general disease" (§ 163). 
But it is worth to remind that these notions, as formulated by Hahnemann, should not be automatically equaled to the current homeopathic concepts of individualization of the case and treatment of the patient's totality. Hahnemann's formulation was grounded on at least four mistaken assumptions:

First, the inner aspects of disease are invisible and cannot be ever known: "It may be granted that every disease must depend upon an alteration in the inner working of the human organism. This disease can only be mentally conceived through its outward signs and all that these signs reveal; in no way whatever can the disease itself be recognized" (§5).

Second, "Whatever removes permanently the complex of outward signs of disease must simultaneously have removed the inward morbid change" (§ 12). Hahnemann can't conceive asymptomatic diseases.

Third, only one disease at a time can exist in a man $(\S 21)$.

Fourth, with some exceptions (see below), diseases are strictly individual. "Nature has no nomenclature or classification of disease. She produces individual diseases" (\$ 46). And "The unimaginable number of different diseases of body and mind; diseases so different that, strictly speaking, it is hardly too much to say that each has only existed once in the world” (§ 60).

Hahnemannian misconceptions are completely understandable considering the state of biological knowledge in his time. But a possible clue indicating that Hahnemann was not thinking in the same way as many homeopaths do nowadays are the exceptions offered by himself:

"Certain diseases are caused by a special agent of contagion (an individual miasm of a sufficiently definite kind), for instance, the plague of the Levant, small-pox, measles, true smooth scarlet fever, venereal disease, the itch of woolmakers, as well as rabies, whooping-cough, plica polonica, etc. These diseases seem to be so definitely distinguished in their course and character that, whenever they appear, they can be recognized by their persistent signs as old acquaintances. Therefore it is possible to give each of them a definite name and to attempt to establish for each of them a regular and staple method of treatment" (§ 49).

In a much more striking and very brief paper published in 1819, Hahnemann states with no hesitation, regarding the treatment of suicides, that "The smallest dose of pulverized gold attenuated to the billionth degree [...] immediately and permanently removes this fearful state of the (body and) mind, and the unfortunate is saved" [8]. Specific homeopathic treatment for precisely diagnosable diseases, this is what he seems to be suggesting here.

In a third and polemic paper in this issue of the IJHDR, Lyn Brieley-Jones hypothesizes that homeopathy should discuss with conventional medicine in terms of its own theoretical framework, with the aim of capitalizing it and avoiding what Berger and Luckmann call the process of "nihilation" of homeopathy when it is discussed in terms of the conventional one [9].

To conclude, despite uncertainties and difficulties homeopaths still have to struggle with, we can only feel grateful to Hahnemann's countless efforts to introduce homeopathy and everything what it means in medicine history and development.

\section{References}


[1] Hahnemann S. Essay on a new principle for ascertaining the curative powers of drugs, with a few glances at those hitherto employed. In: Dudgeon RE, ed. The lesser writings of Samuel Hahnemann. New Delhi: B Jain; [s.d.]

[2] Waisse de Priven S. Hahnemann: um médico de seu tempo. São Paulo: Educ/Fapesp; 2005.

[3] Rogers J. Hahnemann and the methodology of pathogenetic trials in healthy volunteers: a reappraisal. Int J High Dilution Res 2010; 9(32): 94-103.

[4] Rutten L. Bayes' theorem: scientific assessment of experience. Int J High Dilution Res 2010; 9(32): 104114.

[5] Rutten ALB, Stolper CF, Lugten RF, Barthels RJ. Statistical analysis of six repertory-rubrics after prospective assessment applying Bayes' theorem. Homeopathy 2009; 98:26-34.

[6] Ferrater Mora J. Diccionario de filosofía. Barcelona: Ariel; 1994.

[7] Hahnemann S. Organon der rationelle Heilkunde. Dresden: Arnoldische Buchhandlung; 1810.

[8] Hahnemann S. On the uncharitableness towards suicides. In: Dudgeon RE, ed. The lesser writings of Samuel Hahnemann. New Delhi: B Jain; [s.d.].

[9] Brieley-Jones L. Boundaries or bridges: what should Homeopathy's relationship be with mainstream medicine?. Int J High Dilution Res 2010; 9(32): 115-124.

\section{(c)) BY-NC-ND Licensed to GIRI}

Invited Editor: José Enrique Eizayaga, Universidad Maimónides, Argentina, jose.eizayaga@gmail.com .

How to cite this article: Eizayaga, JE. First Edition of Hahnemann's Organon: Celebrating its $200^{\text {th }}$ Anniversary. [editorial]. Int J High Dilution Res [online]. 2010 [cited YYYY Month dd]; 9(32): 90-93. Available from: http://www.feg.unesp.br/ ojs/index.php/ijhdr/article/view/415/446 